\title{
A ANÁLISE DE INTERACÕES DISCURSIVAS EM AULAS DE CIÊNCIAS: AMPLIANDO PERSPECTIVAS METODOLÓGICAS NA PESQUISA EM ARGUMENTAÇÃO
}

\author{
LUIZ GUSTAVO FRANCO ${ }^{1 *}$ \\ ORCID: https://orcid.org/0000-0002-1009-7788 \\ DANUSA MUNFORD $1,2 *$ \\ ORCID: https://orcid.org/0000-0001-7071-4904
}

RESUMO: No presente artigo, discutimos potencialidades da Etnografia em Educação para análise de interações discursivas em aulas de ciências. Um dos desafios da pesquisa em Educação em Ciências interessada no campo da Argumentação é o deslocamento das análises de interações discursivas de um enfoque prescritivo/avaliativo para um olhar mais descritivo/ processual do "argumentar em sala de aula". Apresentamos um desenho de pesquisa desenvolvido em torno de três eixos interdependentes para analisar interações discursivas em uma turma do $3^{\circ}$ ano do Ensino Fundamental. Os resultados indicam que considerar a forma do discurso, e não apenas seu conteúdo, gerou insights sobre o que significa argumentar na perspectiva dos próprios estudantes e professora. Ademais, conexões históricas do cotidiano da turma em contraste com contextos de diferentes dimensões espaço-temporais proporcionaram uma análise multifacetada dos processos de aprendizagem em construção.

Palavras-chave:Discurso; Argumentação; Etnografia em Educação; Metodologia; Educação em Ciências.

\footnotetext{
${ }^{1}$ Universidade Federal do ABC, Centro de Ciências Naturais e Humanas, Santo André, SP, Brasil.

${ }^{2}$ Universidade Federal de Minas Gerais, Faculdade de Educação, Belo Horizonte, MG, Brasil.

"Doutor em Educação pela Universidade Federal de Minas Gerais (UFMG). Professor Adjunto do Centro de Ciências Naturais e Humanas da Universidade Federal do ABC (UFABC). E-mail: < luiz.gfs@hotmail.com >

"* Doutora em Educação (Curriculum and Instruction) pela Pennsylvania State University. Professora Associada do Centro de Ciências Naturais e Humanas da Universidade Federal do ABC (UFABC) e membro do Programa de Pós-graduação em Educação Conhecimento e Inclusão Social da Faculdade de Educação da Universidade Federal de Minas Gerais (UFMG). E-mail:< danusamun@gmail.com >..
} 


\section{THE ANALYSIS OF DISCURSIVE INTERACTIONS IN SCIENCE LESSONS: BROADENING METHODOLOGICAL PERSPECTIVES IN ARGUMENTATION RESEARCH}

ABSTRACT: We discuss the potential of Ethnography in Education to analyze discursive interactions in science lessons. One of the challenges of Science Education research is to shift the studies from a prescriptive/ evaluative approach to a descriptive/procedural view of argumentation in classroom. We present a research design developed around three interdependent axes to analyze discursive interactions in an Elementary School's $3^{\text {rd }}$ grade class. The results indicate that considering the form of discourse, not just its content, has generated insights into what it means to argue from the perspective of students and teacher themselves. In addition, historical connections of the daily life of the class in contrast to contexts of different time-space dimensions provided a multifaceted analysis of the learning processes under construction.

Keywords: Discourse; Argumentation; Ethnography in Education; Methodology, Science Education.

\section{INTRODUÇÃO}

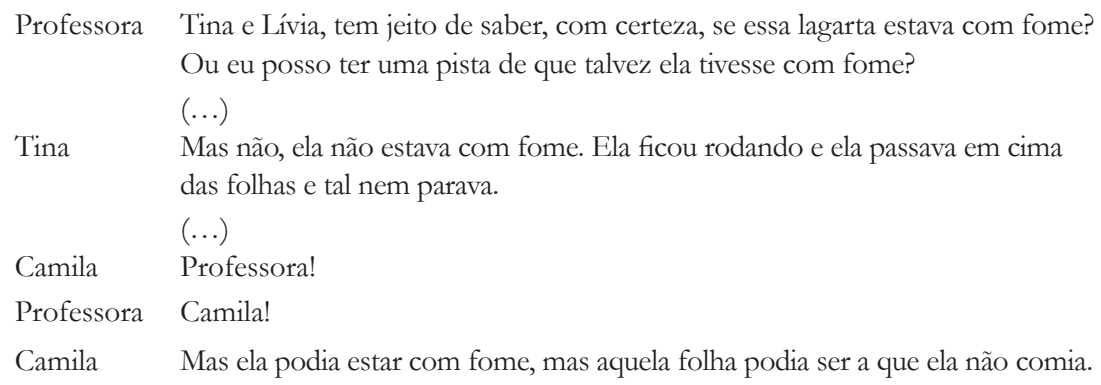

Análises de interações como estas podem contribuir para a compreensão da argumentação em sala de aula? Como tais análises podem dar visibilidade às oportunidades de aprendizagem construídas na escola? Mais especificamente, como podem contribuir com a pesquisa em Argumentação no Ensino de Ciências e o seu papel na aprendizagem de ciências?

A transcrição acima é parte de uma discussão em uma aula de ciências em uma turma que acompanhamos ao longo de três anos. Nesta discussão, as alunas Tina e Camila discordaram e buscavam justificar seus pontos de vista. Discutimos potencialidades de referenciais orientados pela Etnografia em Educação no estudo de interações como esta. Entendemos que estes referenciais podem 
contribuir para uma reflexão acerca do uso de ferramentas de análise alternativas neste campo e gerar novos insights sobre o que significa ensinar e aprender ciências em sala de aula.

Iniciamos com uma discussão sobre Argumentação e os desafios metodológicos na pesquisa acadêmica neste campo, especificamente, na área de Educação em Ciências. Destacamos como a abordagem que utilizamos insere-se nesse contexto. Em seguida, a partir da apresentação da análise de interações discursivas de uma turma do $3^{\circ}$ ano do Ensino Fundamental, discutimos aspectos dos referenciais que adotamos, explicitando certos conceitos, pressupostos e ferramentas teórico-metodológicas. Ressaltamos, em particular, elementos da Análise Microetnográfica do Discurso e da Etnografia Interacional. Dessa forma, as análises dos dados empíricos que apresentamos têm o papel de ilustrar o modo de construção de uma análise, e não responder questões relacionadas a como ocorre a argumentação nesta turma como em outras produções de nosso grupo de pesquisa (FRANCO; MUNFORD, 2017a, 2017b). Em nossas conclusões, sistematizamos implicações dessas propostas para a pesquisa em Educação em Ciências e para o desenvolvimento da argumentação nos contextos escolares.

Desse modo, o objetivo central do artigo é possibilitar a discussão de contribuições dessas abordagens para o estudo de interações discursivas em sala de aula, apoiando-nos explicitamente em experiências concretas de pesquisa sobre a argumentação. Neste sentido, a questão que pretendemos responder é: de que modos uma perspectiva etnográfica pode contribuir para o desenvolvimento de formas de investigar interações em aulas de ciências valorizando a prática argumentativa enquanto processo e dando maior visibilidade à perspectiva dos participantes?

\section{O ESTUDO DA ARGUMENTAC̣ÃO NA SALA DE AULA}

A argumentação é uma atividade comunicativa fundamental na vida humana. Está presente no cotidiano das pessoas, nas atividades profissionais, nas democracias, no cerne do raciocínio filosófico e na atividade científica (BROCKRIEDE, 1990). Essa prática perpassa a vida social humana, desde situações corriqueiras, como quando nos deparamos com um problema cotidiano e precisamos escolher entre certas alternativas, até momentos decisivos, como na constituição da democracia ateniense na Grécia Antiga ou nos debates políticos das sociedades modernas (BAKER, 2009), que, particularmente, temos vivenciado de forma tão intensa na política brasileira. 
No contexto escolar, diversos educadores e pesquisadores, buscando superar um modelo de ensino memorístico, têm se voltado para o estudo da argumentação na escola. "Argumentar" tem sido uma prática importante a ser desenvolvida na sala de aula, e, ao mesmo tempo, é entendida como estratégia para a aprendizagem em diversas disciplinas, como Filosofia, História, Línguas, Matemática e Ciências (MIRZA; PERRET-CLERMONT).

Especificamente, pesquisadores em Educação em Ciências têm tentado compreender como estudantes aprendem a "fazer e falar ciência" ao argumentarem em aulas de ciências através da análise de interações discursivas (MANZ, 2015b). No final dos anos 1990, Driver e colaboradores (1999) já apontavam como essas interações têm grande potencial para gerar oportunidades de aprendizagem de ciências para além de memorização de nomes ou fórmulas, para que os alunos sejam introduzidos em uma forma específica de construir conhecimento e apropriar-se dela. Além disso, desde então, estudos têm evidenciado seu potencial para contribuir no desenvolvimento de processos cognitivos (KUHN, 1993), estimular competências comunicativas, e desenvolver a consciência de que a pesquisa científica é influenciada por uma diversidade de fatores ideológicos e políticoeconômicos (JIMÉNEZ-ALEIXANDRE; ERDURAN, 2008).

A pesquisa em Argumentação é marcada por diferentes enfoques e o estabelecimento de diversas relações com o ensino de ciências. Alguns estudos têm investigado como argumentar influencia e/ou é influenciado pelo contexto instrucional das ciências, através, por exemplo: i) de relações entre certos tipos de atividades, como sequências investigativas, e a argumentação dos estudantes (NAYLOR, KEOGH; DOWNING, 2007; RATZ; MOTOKANE, 2016; SILVA; TRIVELATO, 2017), ii) de interações em sala de aula no desenvolvimento da argumentação (MANZ, 2015a, MONTEIRA; JIMÉNEZ-ALEIXANDRE, 2016), e iii) do papel dos professores no processo de construção de argumentos dos estudantes e formação de professores (FERRAZ; SASSERON, 2017; IBRAIM; JUSTI, 2016; MANZ; RENGA, 2017; SASSERON; CARVALHO, 2014). Outros estudos envolvem também investigações de relações sociais e de poder na argumentação dos alunos (OLIVEIRA, AKERSON; OLDFIELD, 2012; VARELAS et al., 2008), levantamentos sobre as noções que os alunos possuem de argumento e elementos relacionados à argumentação (MCNEILL, 2011; SANDOVAL; ÇAM, 2011), ou ainda, a descrição das mudanças que ocorrem no modo dos alunos 
argumentarem ao longo de um período mais amplo (McNEILL, 2011; RYU; SANDOVAL, 2012).

Estes exemplos ilustram diferentes olhares que têm sido construídos pela comunidade de pesquisa em Educação em Ciências sobre a argumentação. Porém, autores apontam algumas preocupações do ponto de vista teórico-metodológico (BRICKER; BELL, 2008; ERDURAN, 2008; SASSERON; CARVALHO, 2011). Ao analisar interações discursivas para compreender a argumentação, o enfoque da maioria das pesquisas tem sido o produto argumentativo (MANZ, 2015b), por isso, também tem sido considerado relevante o desenvolvimento de metodologias capazes de compreender melhor o processo da argumentação (BRICKER; BELL, 2008). Entendemos que esta busca é fundamental para o avanço das pesquisas em argumentação, uma vez que pode: i) ampliar, no campo da Educação em Ciências, a apropriação de diferentes definições e referenciais de argumentação (BRICKER; BELL, 2008), ii) gerar noções menos cristalizadas do que seria argumentar (MCDONALD; KELLY, 2012), e iii) valorizar aspectos contextuais das interações discursivas em aulas de ciências (FRANCO; MUNFORD, 2017a; YUM; KIM, 2015).

Diversos esforços têm sido feitos no sentido de oferecer alternativas de análise buscando contemplar vários aspectos da argumentação e relacioná-la ao ensino e à aprendizagem de ciências (SCARPA, 2015). Em alguns estudos, por exemplo, o modelo de Toulmin, referencial frequentemente utilizado nas pesquisas (ver TOULMIN, 2006), é associado a outras ferramentas de análise (e.g., indicadores de alfabetização científica, ferramentas da linguística) (OLIVEIRA et al., 2012; SASSERON; CARVALHO, 2011; SCARPA; TRIVELATO, 2013). Outros, por sua vez, têm buscado usar o Modelo de Toulmin com modificações e adaptações aos contextos pesquisados (KNIGHT-BARDSLEY; MCNEILL, 2016; NAYLOR et al., 2007). Por fim, alguns pesquisadores têm se apoiado em outros referenciais da teoria da argumentação como a Pragmadialética de Van Eemeren e colaboradores (FRANCO; MUNFORD, 2017b; MUNFORD, TELES, 2015), as discussões de Walton e colaboradores (JUSTI, MARTINS, IBRAIM, 2017; MARTINS, IBRAIM; MENDONÇA, 2016); e outros referenciais do campo da Linguagem (MERCER et al., 2004).

Nosso grupo de pesquisa tem se voltado para essa questão explorando possibilidades de análise através do uso de aspectos 
da Etnografia em Educação (FRANCO; MUNFORD, 2017a, MUNFORD; TELES, 2015). Dessa forma, no presente artigo pretendemos contribuir para esta discussão, apresentando e discutindo orientações da perspectiva etnográfica em educação com ênfase em construtos da Análise Microetnográfica do Discurso (BLOOME et al., 2005, 2008) e da Etnografia Interacional (CASTANHEIRA et al., 2001; DIXON; GREEN, 2005) para análise da argumentação em aulas de ciências.

Tanto a Análise Microetnográfica do Discurso quanto a Etnografia Interacional reúnem elementos de diferentes tradições do campo da Linguagem, como Etnografia da Comunicação (ver HYMES, 1974), Sociolinguística Interacional (ver GUMPERZ, 1982), Novos Estudos do Letramento (ver STREET, 1993) e Etnometodologia (ver GARFINKEL, 1967). Apesar desta pluralidade teórico-metodológica, os pressupostos e ferramentas de análise destes referenciais constituem um esforço coordenado na tentativa de compreender como pessoas criam e negociam o cotidiano em suas vidas através de interações discursivas (BLOOME et al., 2005; CASTANHEIRA et al., 2001; GREEN; DIXON, 2005). Apresentamos alguns aspectos centrais desses referenciais por meio de uma análise ilustrativa de uma interação em aula de ciências. ${ }^{1}$

\section{ANÁLISE DAS INTERAC̣ÕES: A ARGUMENTAC̣ÃO SOBRE A FOME DA LAGARTA}

A interação transcrita no início deste artigo, apresentada de forma mais completa a seguir, é parte de uma discussão sobre o comportamento de uma lagarta que alunos do $3^{\circ}$ ano haviam observado na aula anterior. Os alunos haviam registrado suas observações e estavam lendo os textos produzidos. Após a leitura da aluna Nara, a professora Karina destacou que, em alguns registros, os alunos observaram algumas coisas e, em outros, eles achavam certas coisas. Por exemplo, "a lagarta está rodando" ou "eu acho que ela está com fome". O comentário sobre a fome da lagarta é particularmente interessante, pois a professora transformou a afirmação da aluna em uma questão que resultou em uma argumentação, conforme transcrito a seguir ${ }^{2}$ (Quadro 1): 
QUADRO 1. Argumentação em torno da fome da lagarta

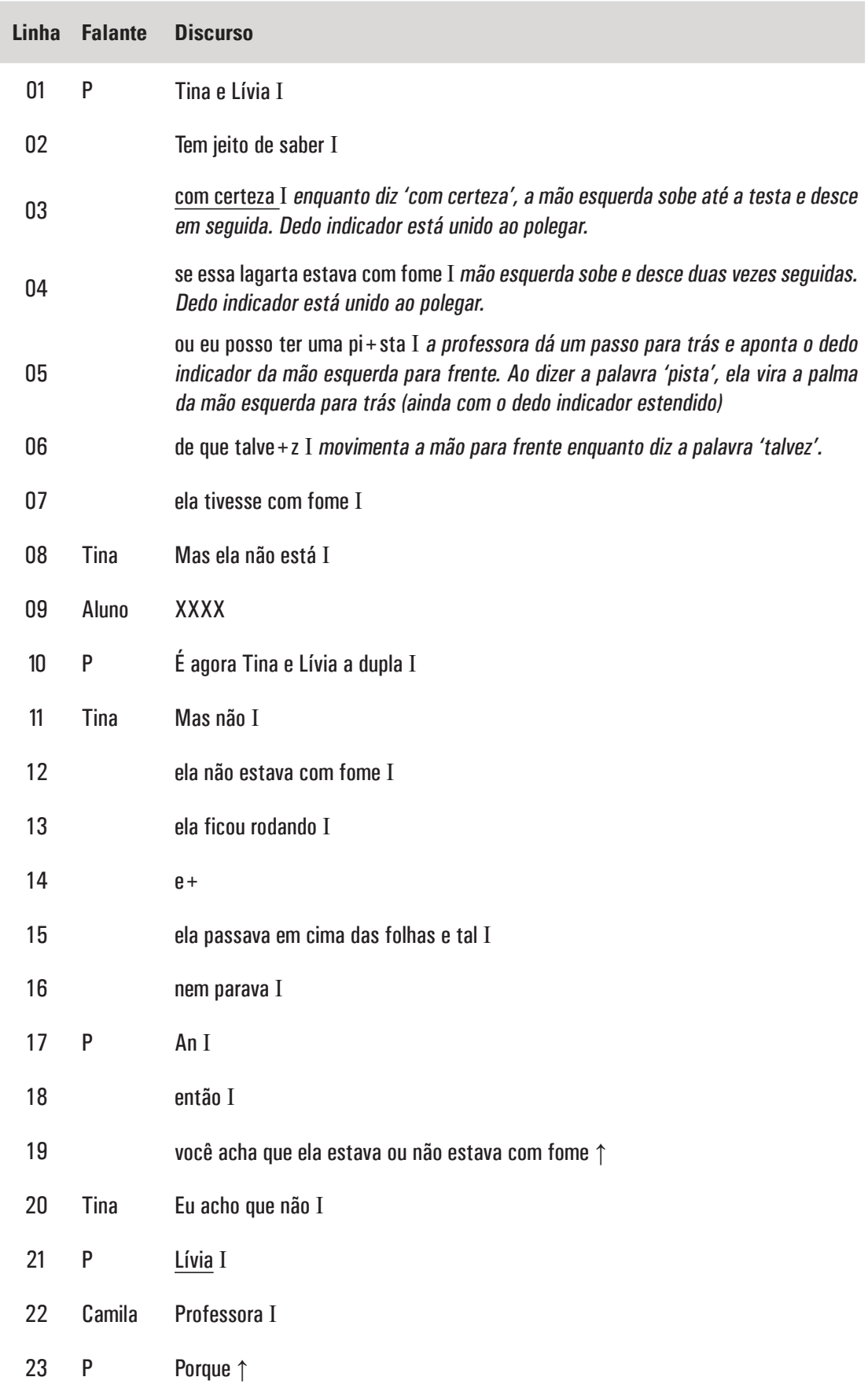


24

25 Lívia Ela estava rodando I

26 mas não comia nada I

$27 \quad \mathrm{P} \quad$ Não comia nada I

28 então acho que tem uma pista não tem $\uparrow$

29

30 Paulo

$31 \quad \mathrm{P} \quad$ Fome ou não fome $\uparrow$

32 Ricardo Não fome I

$33 \quad \mathrm{P} \quad$ Não fome I

34 Camila Professora I

$35 \quad \mathrm{P} \quad$ Camila I

36 Camila Mas ela podia estar com fome I

37 mas aquela folha podia ser a que ela não comia I

$38 \quad \mathrm{P} \quad$ Muito bem I

$39 \quad$ Óh I

40 tinha uma folha I

$41 \quad$ a lagarta não comeu I

42 a lagarta podia estar com fome IIII (pausa de 8 segundos)

43 a lagarta podia estar com fome a Camila acha I

$44 \quad$ mas I

45 se era uma folha que ela não gostava I

46 não comia I

47 e ela passou em cima dela várias vezes e não comeu I

Fonte: Os autores

Analisar uma interação discursiva como esta, apoiando-se em referenciais ligados à Etnografia em Educação indica, a priori, que a intenção do pesquisador é tentarcompreender como as pessoas atribuem 
significados ao seu mundo. No caso de uma análise da argumentação, o pesquisador busca entender como os próprios participantes do grupo experimentam argumentar e dão significados a essa prática.

Para isso, voltamo-nos para o estudo da sala de aula enquanto cultura, investigando como as pessoas "usam a linguagem para agir e reagir umas às outras na construção de um sistema público de significados culturais" (BLOOME, PURO; THEODOROU, 1989, p. 269). Em outras palavras, tentamos compreender como as pessoas, discursivamente, constroem práticas cotidianas, o que tem sido chamado por etnógrafos em educação de "talk into being" (DIXON; GREEN, 2005). A noção de talk into being coloca em destaque a intrincada relação entre discurso e cultura e busca compreender como as pessoas fazem as coisas por meio do discurso, entendendo que o "discurso não manifesta ações: ele é ação" (BLOOME et al., 2008, p. 71). Com o objetivo de dar visibilidade às relações entre discurso e cultura na análise da interação exposta acima, apresentamos nosso caminho metodológico em três eixos relacionados: i) o modo como analisamos a forma desse discurso no contexto imediato da interação, ii) o processo de contextualização histórica dessa interação e iii) a ampliação do nosso olhar para elementos contextuais mais amplos.

\section{A VISIBILIDADE À FORMA DO DISCURSO E ANÁLISE DO CONTEXTO IMEDIATO}

Para compreender como as pessoas "agem por meio de interações discursivas", um aspecto central é a atenção à sua forma e não apenas ao seu conteúdo. Por exemplo, na interação que apresentamos, o direcionamento que o discurso assumiu dependendo da origem das argumentações do grupo é uma maneira de valorizar a forma do discurso. No início da interação, a professora Karina perguntou sobre a possibilidade de se construir uma resposta - "Tem jeito de saber?". Este tipo de questão, a princípio, seria capaz de direcionar a conversa do grupo em torno de uma discussão mais metacognitiva, ou seja, uma discussão relacionada a reflexões sobre como uma resposta poderia ser elaborada (CADZEN, 2001), pois a professora, nesse momento, não questionou diretamente se a lagarta estava ou não com fome. Porém, a aluna Tina alterou esse direcionamento quando ofereceu uma resposta mais direta: "ela não estava com fome". A partir disso, a direção do discurso foi mais no sentido de apresentar os pontos de vista e argumentos, ao invés de pensar em como construir aquela resposta. Posteriormente, com o argumento oferecido por Camila, o grupo permaneceu em uma indecisão e não concluiu se a lagarta estava ou não com fome. 
Para compreender melhor os desdobramentos desse impasse, ampliamos nosso olhar sobre essa interação. Depois desse momento, o grupo começou uma discussão sobre o que poderia ser feito para saber se a lagarta estava com fome. As crianças ofereceram três possibilidades: abrir a lagarta, dar diferentes tipos de folhas e observar a barriga da lagarta. Estas possibilidades estão relacionadas a modos de gerar dados que poderiam auxiliar na construção de uma reposta e resolver a diferença de pontos de vista. Ou seja, as crianças começaram a fazer discussões que se afastaram de uma definição de resposta e passaram a discutir como essa resposta seria construída, retomando um direcionamento mais metacognitivo do discurso.

Além de pensar nesses diferentes direcionamentos do discurso ao argumentar, podemos pensar em outras características contextuais imediatas da fala para dar visibilidade à forma do discurso. Se compararmos a transcrição em turnos de fala que apresentamos no início deste artigo à transcrição da situação que descrevemos agora, percebemos alguns detalhes que não podem passar despercebidos a um olhar etnográfico. Um exemplo é quando a professora pediu por uma evidência utilizando a palavra pista. O uso desta palavra tornou-se significativo para o grupo, o que é evidenciado por algumas características microcontextuais: o alongamento da vogal " $i$ " durante a fala da professora, o acompanhamento dos gestos que deram ênfase, e os acontecimentos que precederam e sucederam o uso dessa palavra. Esta ênfase dada pela professora foi reconhecida pelos outros participantes, o que reflete um significado atribuído pelo próprio grupo e não um significado atribuído a priori pelos pesquisadores.

Se retomarmos os momentos que antecederam esta situação, deparamo-nos com a dicotomia que estava sendo construída entre "achar" e "ter certeza" presente nos registros escritos dos alunos. Quando a professora, através de gestos e entonação, deu ênfase à expressão "com certez̧a", houve uma retomada desse contexto imediatamente anterior. Porém, na interação que apresentamos, há uma diferença importante: ao introduzir a palavra pista, a professora Karina não indicou apenas as possibilidades de "achar" e "ter certeza". Ela ofereceu a noção de um talvez, o que introduziu a possibilidade de um outro modo de construir uma resposta. Ao observamos as consequências imediatas dessa introdução, notamos que as interações posteriores também se mostraram bastante interessantes, uma vez que a reação das alunas Tina, Lívia e Camila à demanda por uma pista - ação da professora - foi a apresentação de um dado observado na aula anterior capaz de sustentar seus pontos de vista, bem como os desdobramentos relacionados ao uso desse dado. 
Esse tipo de análise busca valorizar o modo como as pessoas conversam, e não apenas o conteúdo das colocações. Isso é possível pois transcrevemos as falas em unidades de mensagem e entendemos que sem esta ferramenta dificilmente seríamos capazes de fazer algumas inferências sobre a argumentação do grupo. Green e Wallat (1981) definem a unidade de mensagem como a menor unidade de significado na análise de uma conversação. Para estabelecer os limites entre cada unidade, utilizamos sinais que Gumperz (1982) chama de pistas de contextualização e incluem sinais verbais, não verbais e prosódicos, por exemplo: mudanças de entonação da fala, ritmo, ênfase, velocidade, pausa, postura corporal, gestos, olhares etc. Nas interações, os participantes utilizam estas pistas para sinalizar uns para os outros o que está acontecendo, para que os outros sejam capazes de atribuir significados a suas ações.

O interessante nesse tipo de análise é que as pessoas lançam mão das pistas de contextualização "sem a necessidade de uma consciência explícita do seu uso" (BLOOME et al., 2005, p. 14). Dessa forma, temos acesso a certos sinais que os participantes usam para compartilhar mensagens que poderiam estar invisíveis a um olhar desatento, por exemplo, sentimentos de cortesia ou grosseria, desejo de dar mais ou menos destaque a uma ideia, e maior ou menor engajamento em certa atividade conjunta. No caso da análise que apresentamos, a ênfase na palavra pista, bem como outros elementos microcontextuais, nos deram sinais de que esse recurso fora significativo para o grupo, o que foi corroborado por outras evidências ao longo de nossa investigação. ${ }^{3}$ Evidentemente, entendemos que, ao trabalhar com pistas de contextualização, não se pretende compreender o estado interno das pessoas e suas intenções individuais. Antes, a partir das consequências do que se fala, analisando como as pessoas agem e reagem umas às outras, buscamos interpretar os significados compartilhados pelo grupo a partir da perspectiva dos participantes, objetivo chave da perspectiva etnográfica.

\section{CONSTRUINDO UMA ANÁLISE HISTORICAMENTE LOCALIZADA}

Além do contexto imediato da interação, ou seja, o que acontece durante e imediatamente antes e depois da situação de interesse, a compreensão da cultura do grupo demanda um olhar mais amplo sobre sua história. O uso da palavra pista é um bom exemplo para essa imersão histórica. Para fazer esse tipo de análise, desenvolvemos o que Dixon e Green (2005) chamam de backward/ forward mapping, isto é, percorremos a linha do tempo na história da 
turma na disciplina ciências, voltando a eventos ocorridos no passado e avançando a eventos futuros ao identificarmos outros momentos em que o grupo discutiu o uso de "pistas" (Figura 1).

FIGURA 1. Momentos em que identificamos o uso da palavra pista em discussões do grupo ao longo do tempo

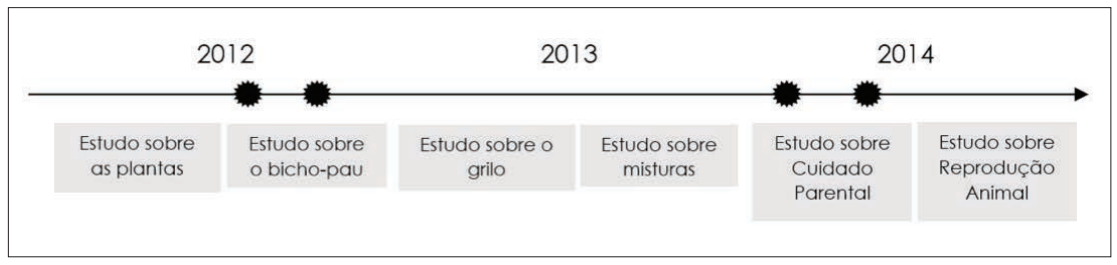

A referência a uma pista apareceu cerca de seis semanas depois da situação que analisamos, em maio de 2014, quando os alunos trouxeram um besouro para a sala:

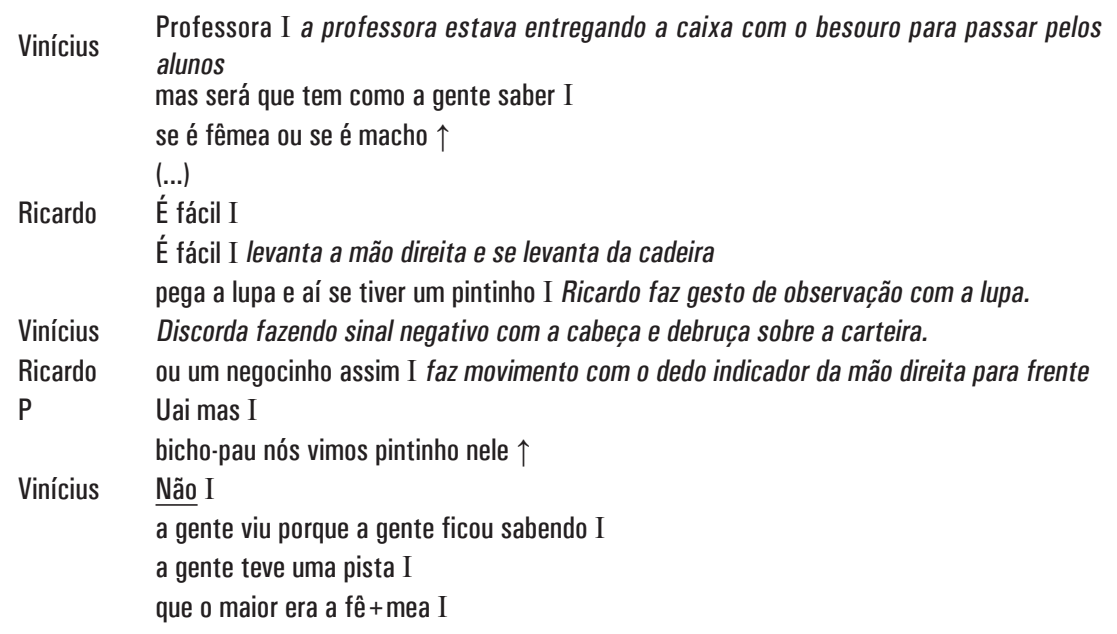

A argumentação, nesse caso, foi gerada pela discordância sobre como fazer a identificação do sexo de um besouro. Para problematizar a sugestão de "olhar por baixo", a professora relembrou o grupo de outro momento, o estudo do bicho-pau. Essa lembrança conectou a discussão que o grupo vivia no presente - sobre o sexo do besouro - e uma discussão vivida há cerca de um ano e meio - sobre o sexo do bicho-pau (ver Figura 1).

Vinícius, ao tomar a palavra, respondeu o questionamento da professora dizendo que eles tiveram uma pista, quando tentaram identificar o sexo do outro animal. Essa referência é significativa, uma vez que, o aluno fala de uma pista para indicar um dado que sustentou a construção de uma resposta em outro momento da 
história, o que indica uma continuidade no uso dessa palavra. Porém, uma mudança é que, dessa vez, foi um aluno que falou em uma pista, ao discordar da proposta do colega Ricardo. $\mathrm{Na}$ sequência, outras crianças interagiram e se engajaram em uma narrativa para rememorar as pistas que, juntos, usaram para identificar o sexo do bicho-pau, por exemplo, o tamanho dos animais. Essa narrativa evocou um momento vivenciado em grupo no passado, o que é chamado por Bloome et al. (2009) de memória coletiva e nos levou a um retorno na história da turma, especificamente, no segundo semestre de 2012 (ver Figura 1), quando as crianças estudavam a biologia do bicho-pau.

Uma memória coletiva trata-se de uma "narrativa sobre eventos passados publicamente reconhecida pelos membros de um coletivo e à qual os membros respondem" (GRIKORENKO, BEIERLE; BLOOME, 2014, p. 65). Através destas memórias, o grupo constrói relações intercontextuais, o que é de grande significância para uma análise historicamente situada. A intercontextualidade "refere-se à construção social das relações entre eventos e contextos" (BLOOME et al., 2009, p. 319). Nessa construção, professores e estudantes evocam suas memórias coletivas para, por exemplo, assumirem, em conjunto, a responsabilidade sobre eventos do passado relacionados aos tópicos que estão sendo estudados no presente (GRIKORENKO et al., 2014). Esse tipo de construto é relevante para a análise que propomos. No caso da situação que apresentamos, as crianças engajaram-se na narrativa sobre como algumas pistas foram utilizadas naquele outro momento. Isso indica um aspecto significativo no modo particular de argumentar que essa turma estava construindo ao longo do tempo: recorrer a dados para sustentar seus pontos de vista.

Em nossas análises, esse retorno ao passado nos levou à identificação do uso da palavra pista nas discussões orais em uma aula de novembro de 2012. Nesta ocasião a turma observava alguns bichospau que estavam em um aquário dentro da sala de aula. Em uma dessas observações, os alunos identificaram um bicho-pau supostamente morto no aquário e iniciaram uma discussão sobre a possível origem daquele bicho-pau e se estava, de fato, morto. Uma das sugestões dos alunos era que o macho e a fêmea, que ainda estavam vivos no aquário, 'se casaram' e a fêmea botou um ovo que deu origem àquele bicho-pau que, depois, morreu. $\mathrm{O}$ aluno Ricardo sugeriu que, se isso fosse verdade, haveria uma casca de ovo dentro do aquário. Nesse caso, surgiu uma argumentação gerada por essa discordância entre os alunos, uma vez que Ricardo colocou em dúvida a sugestão dos colegas. Nessa situação, Vinícius foi observar o aquário para tentar encontrar a casca do ovo e a professora perguntou: 
P Você achou alguma pista $\uparrow$

ovo quebrado I

ou casca de ovo $\uparrow$

Nesta aula a professora introduziu a palavra pista na discussão com Vinícius para falar sobre um dado que ajudaria a resolver a discordância. Vinícius não encontrou nada e o grupo descartou a possibilidade de a fêmea ter botado um ovo. Outras propostas de explicação foram discutidas em grupos e, posteriormente, eles descobriram que era apenas o exoesqueleto, ou como as crianças chamaram, a casca do filhote que passara por um processo de ecdise.

Essas relações intercontextuais orientam o pesquisador em como se mover temporalmente entre eventos que os próprios participantes estão reconhecendo como significativos para o grupo. A partir de contrastes entre esses momentos, podemos reconhecer continuidades ou mudanças na prática argumentativa ao longo do tempo e compreender o uso que a turma fez da palavra pista, enquanto recurso semiótico significativo na construção de um modo específico de argumentar. As características da argumentação nesses diferentes contextos podem ser representadas pela Figura 2:

FIGURA 2. Representação de relações intercontextuais na argumentação do grupo em diferentes momentos da história em que se usa a palavra pista

\begin{tabular}{|c|c|c|c|c|}
\hline \multicolumn{3}{|c|}{ Relações intercontextuais na argumentação do grupo } \\
\hline $\begin{array}{c}\text { O QUE É CONSIDERADO } \\
\text { UMA PISTA? }\end{array}$
\end{tabular}


Para aprofundar este tipo de análise, um movimento interessante seria a busca por outros momentos relacionadas ao uso desse recurso semiótico. Em nossas análises, chegamos a identificar algumas situações significativas neste sentido. Em setembro de 2012, por exemplo, o grupo se preparava para sair pela escola observando animais que eles poderiam estudar nas aulas de ciências. Os registros em nosso caderno de campo indicaram que, antes de saírem, a professora destacou que talvez as crianças não conseguiriam ver um bicho, mas eles poderiam ver outras coisas dos bichos. Alguns alunos ofereceram exemplos, como rastejo de cobra, pegadas, farelos e teias de aranha. Karina, então, concordou com os exemplos dos alunos e comentou: "Não é o bicho, mas é uma pista do bicho". Durante a saída de campo, as crianças identificaram diversas dessas pistas e o aluno Ramon, trazendo uma folha com cocô de passarinho, exclamou: "Karina, uma pista?"

Esse foi o primeiro evento em que identificamos em nossos registros o uso da palavra pista. Interessante que sua introdução ocorreu em um contexto não argumentativo. Não havia neste caso uma discordância em torno de alguma questão ou uso de argumentos para defender ou refutar pontos de vista. Já em eventos posteriores; como em novembro de 2012, março e maio de 2014; uma mudança: a palavra pista passou a ser usada para indicar dados capazes de sustentar pontos de vista, aspecto relevante na construção da argumentação da ciência escolar.

Contudo, se avançamos na linha do tempo da história da turma, após a discussão sobre o sexo do besouro em maio de 2014, percebemos nos registros de caderno de campo que a palavra pista deu lugar a outra palavra. Nas argumentações futuras a turma usou a palavra evidência para fazer referência aos dados que sustentavam pontos de vista, identificada com recorrência em discussões posteriores, no segundo semestre de 2014.

Para uma análise mais acurada desse processo de mudança, seria necessário um aprofundamento maior na história do grupo para compreender melhor como se deu esse processo. Como indicado por Green et al. (2013, p. 128, tradução nossa), seria necessário "mapear o passado até as raízes de um processo particular, práticas e fontes de conhecimento, entre outros fenômenos culturais, ou mapear o futuro no tempo até descobrir as rotas do conhecimento cultural necessário para entender o fenômeno como os membros o fazem".

Ainda pensando sobre relações intercontextuais, o contraste entre diferentes eventos envolvendo argumentação indicou-nos uma continuidade na forma do discurso da turma. O contraste entre a discussão sobre a fome da lagarta e as outras argumentações 
indicou dois movimentos discursivos: ora direcionado no sentido de apresentação de pontos de vista e argumentos, ora direcionado no sentido de discutir como construir respostas (Figura 3).

FIGURA 3. Direcionamento do discurso na argumentação do grupo em diferentes momentos da história

\begin{tabular}{|c|c|c|c|c|}
\hline \multicolumn{5}{|c|}{ Como o grupo direcionou o discurso durante a argumentação? } \\
\hline $\begin{array}{l}\text { Apresentando ponto } \\
\text { de vista e } \\
\text { argumentos }\end{array}$ & $\begin{array}{l}\text { Discutindo } \\
\text { como construir } \\
\text { respostas }\end{array}$ & $\begin{array}{l}0 \text { que era } \\
\text { discutido? }\end{array}$ & & Quando? \\
\hline$\downarrow$ & 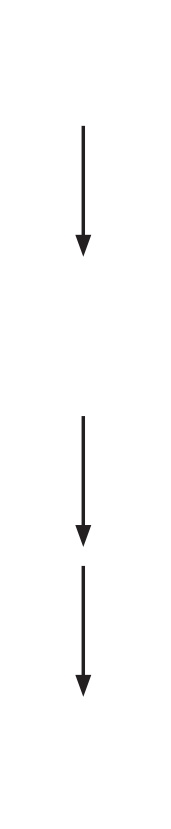 & $\begin{array}{c}\text { O bicho-pau é macho } \\
\text { ou fêmea? } \\
\text { Como saber se o bicho-pau } \\
\text { é macho ou fêmea? } \\
\text { A lagarta estava } \\
\text { com fome? } \\
\text { O que podemos fazer para } \\
\text { descobrir se a lagarta } \\
\text { estava com fome? } \\
\text { Tem como saber } \\
\text { se o besouro é macho } \\
\text { ou fêmea? } \\
\text { O besouro é macho } \\
\text { ou fêmea? }\end{array}$ & 2012 & 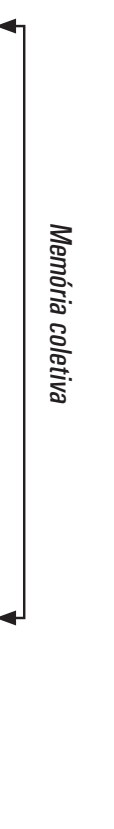 \\
\hline
\end{tabular}

Este modo oscilante do grupo argumentar não significa que nossa descrição busca indicar um modelo padrão que as crianças sempre seguiam em suas discussões. Antes, o que destacamos é uma continuidade na construção da prática argumentativa que evidencia semelhanças entre situações ocorridas em diferentes momentos na história. Porém, mesmo dentro dessa continuidade, existem mudanças relevantes. Por exemplo, não há padrão na ordem em que cada tipo de questão emergiu nas discussões ou em quem propôs a questão (professora ou estudante). 
Esse tipo de análise foi possível por meio de um desenho de pesquisa baseado em pressupostos teóricos-metodológicos que valorizam essa percepção histórica, como é o caso da Etnografia em Educação (Figura 4).

FIGURA 4. Representação da construção de uma análise histórica do grupo

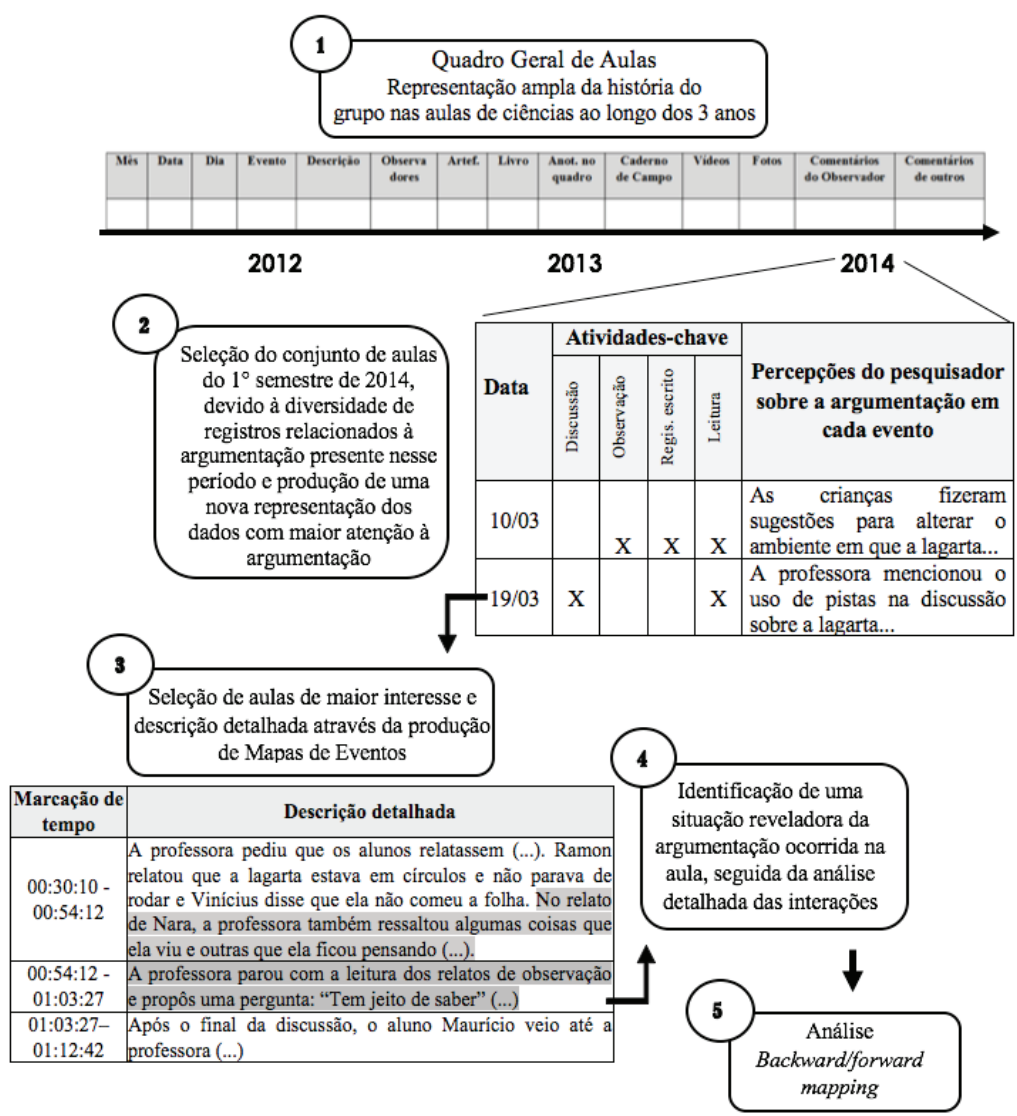

A figura 4 indica que, a partir de uma visão holística da história do grupo, fomos capazes de identificar e dar maior destaque para situações mais expressivas com relação a nosso problema de pesquisa. No caso de nosso estudo, por exemplo, no momento inicial das análises, fizemos uma imersão no conjunto de eventos com interesses mais abrangentes e construímos algumas representações que nos ofereceram uma visão panorâmica da história da turma na 
disciplina ciências ao longo dos três anos que os acompanhamos. O Quadro Geral de Aulas e o recorte de um conjunto de aulas de um determinado momento da história (CASTANHEIRA et al., 2001) análises 1 e 2 da Figura 4, são exemplos desse tipo de representação.

Ao longo deste processo, buscamos identificar interações em que havia momentos de discordância de pontos de vista e apresentação de argumentos para defendê-los ou refutá-los, uma vez que nosso objetivo era compreender a prática de argumentação (VAN EEMEREN et al., 2002). Com essas representações, estabelecemos relações entre parte-todo e começamos a localizar algumas situações particulares nessa história (GREEN, DIXON; ZAHARLIC, 2005), representadas pelos Mapas de Eventos em que descrevemos com detalhamento o que acontecera em algumas aulas em que identificamos a argumentação - análise 3 da Figura 4.

Esse tipo de desenho de pesquisa segue uma lógica de telling case (MITCHELL, 1984). Por meio dessa lógica buscamos identificar uma situação reveladora e descrevê-la em detalhe. Nesse estudo selecionamos uma situação que se mostrou particularmente surpreendente: o uso binômio dadoàconclusão não foi suficiente para resolver uma discordância, como tipicamente já acontecia em outras argumentações da turma. O dado oferecido por Tina, rodar sobre a folha e não comer, não colocou fim à questão sobre a fome da lagarta. Um novo argumento, a possibilidade das folhas serem das que a lagarta não gosta, apontado por Camila, colocou em xeque o modo como o dado estava sendo interpretado, o que gerou interessantes desdobramentos na argumentação - análise 4 da Figura 4.

A potencialidade da análise deste tipo de situação reside justamente na quebra daquilo que é rotineiro. Quando nos deparamos com esses momentos, encontramos situações em que o fluxo ordinário da vida cotidiana é rompido e aquilo que já se tornara invisível na cultura do grupo fica exposto, ganha visibilidade e é capaz de revelar algum aspecto da vida daquela turma (AGAR, 1994).

Importante destacar que, ao discutirmos com maior profundidade uma breve interação, não estamos utilizando a lógica da tipicalidade ou detalhando um "caso ilustrativo" daquilo que era recorrente no grupo. Nosso objetivo é dar destaque a uma situação que torna as particularidades de um grupo mais evidentes com relação a um determinado fenômeno social.

Além disso, é importante retomar que o enfoque em um ou poucos eventos não significa um recorte descontextualizado na história de um grupo. Uma vez selecionada a situação de interesse, em nosso caso, a discussão sobre a fome da lagarta, foi possível, 
então, fazer um movimento de retorno à história ampla da turma para percorrer outros episódios e estabelecer conexões significativas (backward/forward mapping) - análise 5 da Figura 4.

Como indicamos através de nossos exemplos de análise, nestas conexões, nosso interesse não foi comparar eventos e dizer se as crianças estavam argumentando melhor ou pior, mas destacar processos de continuidades e mudanças, para identificar transformações na argumentação do grupo ao longo do tempo (BLOOME et al., 2013). Dessa forma, não há a pretensão de estabelecer generalizações padronizantes sobre a argumentação ou avaliar os produtos argumentativos dos estudantes e sim analisar como um grupo negociou, reformulou e construiu esta prática.

Ao discutirmos esta análise historicamente situada não foi nosso objetivo 'recontar' toda história do grupo relacionada à argumentação ou esgotar o que o grupo construiu com relação a esta prática. A análise remete-se a uma visão de que, se as crianças argumentam de certa forma, isso está conectado a outras relações que foram estabelecidas em eventos no passado e também terá conexões às formas de construir esta prática em eventos futuros (BLOOME et al., 2013). Como ilustramos com as análises nesta seção, o objetivo é estabelecer conexões com outros momentos vivenciados pela turma a fim de obter evidências de que o que acontece naquele evento é algo significativo para aquele grupo, aspecto fundamental em uma perspectiva etnográfica.

\section{AVANÇANDO PARA CONTEXTOS MAIS AMPLOS}

Até aqui, analisamos características imediatas da interação discursiva que apresentamos, estabelecemos conexões com interações imediatamente anteriores e posteriores, além de fazermos uma análise com base na história do grupo em aulas de ciências. Porém, entendemos que a prática da argumentação, bem como outras práticas cotidianas não estão isoladas das histórias de vida das pessoas ou das instituições sociais em que estamos inseridos. Como indicado por Bloome et al. (2008),

[...] enquanto as pessoas vivem "localmente" as suas vidas, interagindo umas com as outras, movendo-se através de eventos, elas também são influenciadas por processos sociais, culturais, políticos, econômicos e históricos que existem muito além das situações locais em que as pessoas interagem (p. 24).

Dessa forma, uma abordagem que busca valorizar a perspectiva dos participantes deve levar em consideração as relações entre diferentes contextos em sala de aula. Esses diferentes contextos são elementos históricos, múltiplos e interativos (BLOOME et al., 2008) provindos de diferentes dimensões espaço-temporais (BLOMMAERT, 2015) 
que se articulam no cotidiano. Isto é, o que acontece nas interações imediatas da sala de aula está articulado a diversos aspectos, como a história da turma, os papéis sociais e trajetórias de seus participantes, a comunidade escolar, o currículo, as agendas das instituições sociais em que as escolas estão inseridas, as vivências familiares, as políticas públicas relacionadas à educação, além de relações de poder e questões de raça, gênero, classe, etc. (BLOOME et al., 2008).

Uma forma de dar visibilidade a diferentes contextos é questionar, por exemplo, quem são os participantes da pesquisa e estabelecer contrastes com contextos mais amplos (GUMPERZ, 1982; HYMES, 1974). No caso da interação que apresentamos, seria questionar sobre quem são as crianças dessa turma e quem são os participantes que protagonizam a situação de análise. Estas crianças passaram por diferentes instituições de Educação Infantil antes de ingressar no $1^{\circ}$ ano. O ingresso ocorreu mediante sorteio, o que se reflete na diversidade encontrada no grupo. Diversidade aqui é considerada a partir das diferentes experiências escolares e a heterogênea caracterização étnica e socioeconômica da turma, conforme a tabela $1 .^{4}$

TABELA 1. Características demográficas do grupo de crianças investigado

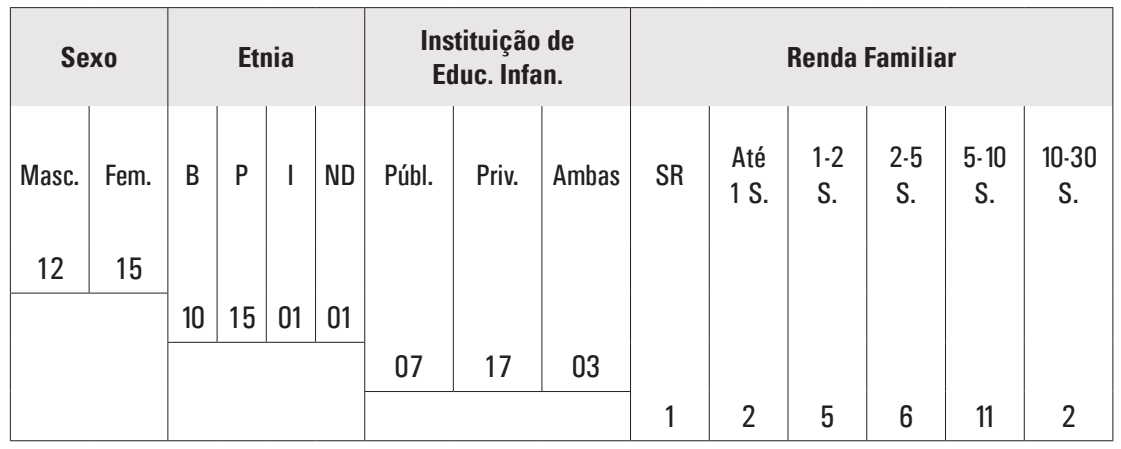

Para além dessa caracterização demográfica, éimportante pensar em cada estudante, suas histórias e trajetórias. Nesse contexto diverso, destacamos as figuras de Tina, Camila e Karina que protagonizam a situação de análise. À primeira vista, Tina e Camila possuem perfis demográficos semelhantes: ambas são meninas, de classe média baixa e pardas. Estes perfis, a priori, poderiam indicar uma tendência a processos de exclusão ou fracasso escolar destas alunas em ciências. Porém, uma imersão nas trajetórias de ambas na história da turma nos revelam outras características que não podem ser negligenciadas.

Essas trajetórias foram caracterizadas a partir de diversas fontes: observação participante, compartilhamento de informações 
entre os pesquisadores que acompanharam o grupo, registros nos quadros de aulas, cadernos de campo, fichas avaliativas e outras representações dos dados. A história de Tina pode ser caracterizada como de expressiva participação na sala de aula, performance acadêmica com ótima avaliação e liderança entre os colegas. Algumas características de Tina que se destacam é que ela defendia suas ideias, interagia muito bem com os colegas e tinha reconhecimento do restante do grupo. Karina confiava tarefas "importantes" à Tina e parecia "contar com ela" nas discussões, uma vez que a aluna, em geral, opinava de forma pertinente e era ouvida pelos colegas.

Camila, por sua vez, apresenta uma trajetória bastante distinta. Apesar de ser caracterizada como muito participativa, nossas análises indicam que Camila era uma aluna considerada ríspida e com problemas de inclusão pelas dificuldades de relacionamento com os colegas. Com frequência alterava a voz durante as discussões e tinha dificuldades em respeitar os direitos de fala dos colegas e, inclusive, da professora. Karina sempre buscava incluir Camila nas discussões. Esta característica da professora é bastante expressiva nas aulas de diferentes disciplinas em que lecionava. Eram comuns eventos em que Karina tentava trazer para discussões e tarefas os alunos com dificuldades de inclusão.

$\mathrm{Na}$ interação que analisamos, Tina, ao ser questionada pela professora, deu uma resposta aparentemente suficiente: forneceu um dado baseado em sua observação do animal para sustentar sua resposta. Isso poderia colocar um ponto final na discussão. O ponto de vista de Camila, porém, foi exposto mediante a solicitação da própria aluna. Camila pediu o direito de fala e o recebeu da professora. A atenção que o argumento de Camila recebeu no contexto dessa discussão está muito relacionado à mediação de Karina. A professora deu uma visibilidade expressiva à fala de Camila o que foi evidenciado pelos desdobramentos desse evento e a necessidade de novas discussões para tentar resolver a discordância que permanecera.

Particularmente nesse caso, essa prática inclusiva de Karina possui implicações diretas sobre o contexto instrucional do ensino de ciências. A expressividade das opiniões que Tina tem diante da turma é bastante diferente da de Camila, o que poderia levar a um possível apagamento da posição desta, caso a argumentação tivesse ocorrido apenas entre as alunas. A visibilidade que o argumento de Camila recebeu possibilitou uma argumentação mais complexa do que o simples binômio Dado>Conclusão que não ocorreu de forma tão linear e direta como em outros casos recorrentes na história do grupo. O argumento de Camila impediu a resolução da dúvida e, com 
a permanência da discordância, o grupo engajou-se em discussões de caráter metacognitivo, o que tem expressiva importância para a construção do conhecimento científico escolar.

Assim, nossa análise, ao interpretar a argumentação de modo mais amplo, deu visibilidade às relações entre o contexto social e o contexto instrucional, uma vez que consequências sociais de inclusão da aluna Camila foram relacionadas à ampliação das oportunidades de aprendizagem de ciências naquela interação.

Além disso, para compreender outras dimensões os processos de aprendizagem em construção nessa interação, poderíamos estabelecer contrastes com outros contextos mais amplos, por exemplo, os contextos institucional e curricular em que a turma estava inserida. A escola que investigamos, localizada em uma metrópole brasileira, é considerada referência em métodos inovadores de ensinoaprendizagem e possui um corpo docente com alto nível de formação. Além disso, a pesquisa foi desenvolvida nas aulas da professora de referência da turma, a professora Karina, que dava aulas de Língua Portuguesa e Tópicos Integrados (Geografia, História e Ciências). Karina é pedagoga, atuava na área educacional há cerca de 25 anos e tinha uma formação acadêmica de qualidade (curso de especialização, mestrado e doutorado). O caso dessa professora, apesar de muito particular, ou até mesmo fora da realidade das salas de aula brasileiras, possui aproximações dos contextos mais comuns dos Anos Iniciais do Ensino Fundamental. Como a maioria das professoras pedagogas, Karina tinha maior expertise na área de linguagem e um contato limitado com o ensino de ciências (ver APPLETON, 2008; PIZARRO, BARROS; LOPES JUNIOR, 2016).

Com relação ao contexto curricular, as aulas de ciências ao longo desses três anos foram planejadas por membros da equipe de pesquisa em parceria com a professora. A perspectiva de ensino que guiou as aulas foi o Ensino de Ciências por Investigação, buscando oferecer às crianças oportunidades para aprender a "fazer" e "falar" ciências na escola (MUNFORD; LIMA, 2007; CARVALHO, 2013). Esta abordagem foi usada para nortear o planejamento em torno de alguns aspectos essenciais a serem desenvolvidos em sala de aula. Dentre esses aspectos, destacamos que as crianças tiveram oportunidades para "se engajar com perguntas de orientação científica, dar prioridade às evidências ao responder questões, formular explicações a partir das evidências, avaliar suas explicações à luz de outras alternativas, comunicar e justificar as explicações propostas" (NRC, 2000, p. 20).

Estes contextos que ultrapassam os limites de uma sala de aula (institucional e curricular) também constituem este espaço e têm influência 
sobre as formas de participação expressiva das crianças ao argumentar, o que é pouco comum em outros cenários, e ajuda a compreender a espontaneidade da turma nas discussões. Porém, entendemos também que há fatores relacionados às práticas cotidianas que lançam luzes sobre essa compreensão a partir de especificidades do próprio grupo.

Um exemplo é a prática comum dessa professora de, durante discussões em sala de aula, manter conversas com um ou mais alunos que eram convidados a estar em frente a toda turma para expor sua opinião. Nestas interações, ela pedia que as crianças falassem olhando para os colegas, ou posicionava fisicamente as crianças voltadas para frente, e chamava para a frente aqueles que expressassem opiniões diferentes. Nós observamos estas ações tanto em aulas de ciências quanto em aulas de língua portuguesa, o que indica que não era algo relacionado, especificamente, à prática de argumentação em ciências. Dessa forma, mesmo a professora tendo pouca experiência com o ensino de ciências, usava essa prática rotineiramente desenvolvida em outra disciplina, o que teve forte relação com a argumentação em ciências. As estruturas de participação da turma, portanto, podem estar relacionadas a certos padrões da cultura deste grupo e não apenas a especificidades do campo disciplinar de ciências. Isto é, algo próprio do "fazer sala de aula" desse grupo interferiu no modo de construir a argumentação em aulas de ciências.

O que queremos indicar com esses exemplos de análise é que, ao recorrer a características de contextos provindos de diferentes dimensões espaço-temporais (história da turma, trajetórias dos participantes, currículo, práticas institucionais), devemos buscar compreendê-los de forma articulada ao que se observa no cotidiano da sala de aula (BLOOME et al., 2008). A forma de estabelecer relações entre esses diferentes contextos pressupõe, na abordagem que adotamos, que professores e alunos não estão apenas engajados em um processo predeterminado de reprodução cultural e social. Sob influência de pressupostos da Etnometodologia, entendemos que os professores e estudantes não são "culturalmente dopados", ou seja, não são meros atores que reproduzem scripts sociais predeterminados (GARFINKEL, 1967). Destacamos esta noção para indicar que há uma série de elementos de contextos mais amplos presentes na sala de aula, mas o modo como, no cotidiano, um determinado grupo se adapta, resiste ou criativamente transforma esses elementos também é fundamental para a compreensão de como esse grupo constrói sua história e dá seus significados a ela (BLOOME et al., 2005).

Ao finalizarmos essa análise, indicamos ainda que poderíamos avançar nessa discussão e aprofundar na compreensão de outras 
dimensões espaço-temporais. No presente artigo apenas iniciamos uma discussão sobre como alguns dos contextos social, institucional, $e$ curricular interpelaram oportunidades de aprendizagem de ciências na turma, particularmente nos aspectos ligados à argumentação.

Entendemos que há diversas outras possibilidades que poderiam ser abordadas, como aspectos econômicos, relações de poder, questões de gênero e raça, vivências familiares, etc. Já existe um movimento de pesquisadores que analisam interações discursivas que buscam agregar as contribuições desses diferentes contextos nos processos de ensino e aprendizagem de ciências. Porém, tais produções ainda são escassas, apesar de seu grande potencial analítico, conforme discutimos em Franco e Munford (2018). Análises dessa natureza podem gerar novos olhares sobre o que acontece no cotidiano da sala de aula, o que, evidentemente, exige um esforço analítico maior. Reconhecer essas dimensões traz implicações diretas para a compreensão dos significados da natureza das práticas sociais em aulas de ciências.

\section{CONTRIBUICִÕES DA ETNOGRAFIA EM EDUCAÇÃO PARA O ESTUDO DE INTERAÇÕES DISCURSIVAS E PARA A PESQUISA EM ARGUMENTAÇÃO}

A pesquisa em Educação em Ciências indica a relevância da introdução de estudantes em certas práticas, como argumentação, como alternativa ao ensino memorístico. Ao estudar esta prática, pesquisadores têm buscado alternativas metodológicas para analisar a argumentação em sala de aula enquanto processo. Neste artigo, apresentamos alguns pressupostos teórico-metodológicos da Etnografia em Educação por meio da análise de interações discursivas. Especificamente, abordamos aspectos da Análise Microetnográfica do Discurso e da Etnografia Interacional a fim de dar maior visibilidade à perspectiva dos participantes, enquanto construtores da cultura da sala de aula por meio de interações momento a momento.

Uma contribuição significativa da abordagem que apresentamos refere-se à discussão entre forma e conteúdo na análise de interações. Buscamos valorizar a forma do discurso destacando, por exemplo: i) pistas contextuais da fala dos participantes, ii) suas estruturas de participação no evento de análise e iii) diferentes direcionamentos dados às interações durante a argumentação. Ao dar mais atenção a como as pessoas falam (forma), proporcionamos maior visibilidade ao processo de construção da prática argumentativa e não apenas aos produtos da argumentação.

Outra contribuição é a proposta de uma análise historicamente situada. Destacamos o uso de recursos semióticos, como a palavra 
pista, e situações relacionadas temporalmente, para descrever continuidades e mudanças na argumentação sem preocupação em avaliar se as crianças argumentavam melhor ou pior. Para contrastar diferentes situações, baseamo-nos em relações intercontextuais criadas pelo próprio grupo, utilizando, por exemplo, memórias coletivas evocadas pelos participantes.

Dessa forma, entendemos que também valorizamos a argumentação como algo que não se restringe aos produtos argumentativos observados em um determinado evento comunicativo, mas algo historicamente situado, construído de forma processual e em conexão com elementos contextuais mais amplos. Com relação a essa conexão, iniciamos uma discussão sobre como contextos provindos de diferentes dimensões espaço-temporais podem ser relacionados à argumentação em sala de aula, destacando: i) o papel da inclusão que a professora promovia nas discussões da turma, o que teve desdobramentos sociais e instrucionais na situação analisada, e ii) as características do contexto institucional e curricular em que a turma estava inserida. Indicamos a relevância de se estabelecer contrastes entre contextos mais amplos ao aqui e agora do cotidiano do grupo.

Nos alinhamos à visão de Kelly (2005) em sua defesa da importância de estudos de caráter etnográfico em Educação em Ciências e suas potencialidades ao indicar implicações educacionais. Como destacado pelo autor, uma forma de desenvolver este tipo de perspectiva é associar a análise de práticas do cotidiano de um grupo a construtos da pesquisa em Educação em Ciências. Entendemos que as análises que apresentamos são um bom exemplo de como estabelecer esse tipo de relação: associamos a análise etnográfica às noções de argumentação que a área tem construído.

Esta abordagem, mesmo se tratando da análise de uma situação muito específica, gera expressivas implicações para formulação de políticas públicas educacionais e para a prática pedagógica, devido a seu caráter fortemente descritivo. Primeiramente, poderíamos pensar, por exemplo, sobre a viabilidade da inserção de práticas científicas mais complexas entre crianças, o que apesar de já estar presente em currículos mais inovadores, ainda precisa ser bastante debatido na elaboração de propostas nacionais, como indicamos em Franco, Almeida e Cappelle (2016). Ainda mais agora, quando observamos alterações na terceira versão Base Nacional Comum Curricular que diminui consideravelmente a visibilidade de práticas investigativas e linguagem da ciência na proposta de Ciências da Natureza para o Ensino Fundamental.

Além disso, as crianças nos primeiros anos do Ensino Fundamental estão estabelecendo contatos iniciais com os processos 
de construção de conhecimento em aulas de ciências e um elemento particularmente importante refere-se à elaboração de respostas nesse campo disciplinar. Nesse sentido, um dos objetivos da argumentação é ajudar a criança a aprender a usar evidências para sustentar suas afirmações. No caso do evento que apresentamos, esta prática começou a ser construída mesmo antes que se falasse em evidências, através de demarcações em torno de respostas "com certeza" e respostas provindas de opinião pessoal (para maior detalhamento dessa discussão, veja FRANCO; MUNFORD, 2017a). Abordamos também as questões metacognitivas através das quais a turma engajouse em discussões sobre como gerar dados para resolver discordâncias em diferentes momentos da história (para maior detalhamento dessa discussão, veja FRANCO; MUNFORD, 2017b). Todos esses pontos possuem implicações relevantes para a compreensão sobre os processos de aprendizagem de ciências na sala de aula.

Finalmente, nossas análises indicaram alguns aspectos ainda pouco compreendidos e que são relevantes para a prática pedagógica, por exemplo: como uma professora pedagoga usa os elementos de sua expertise em outra área de conhecimento para contribuir em sua performance como professora de ciências? Como processos de inclusão/exclusão dos pares ou da professora podem estar relacionados à argumentação em aulas de ciências? Como diferentes dimensões espaço-temporais se articulam às interações das crianças em sala de aula? Tais questões têm fomentado novas análises em nosso grupo de pesquisa e nos colocam novos desafios na compreensão de oportunidades de aprendizagem de ciências em sala de aula.

\section{REFERÊNCIAS BIBLIOGRÁFICAS}

AGAR, M. Language shock: Understanding the culture of conversation. New York: William Morrow and Company. 1994.

APPLETON, K. Elementary science teaching. In: ABELL, S. K.; LEDERMAN N. G. (ed.), Handbook of Research on Science Education (p. 493-535). Mahwah, NJ: Lawrence Erlbaum Associates, Publishers, 2008.

BAKER, M. Argumentative interactions and the social construction of knowledge. In: MIRZA, N. M.; PERRET-CLERMONT, A. N. (ed.). Argumentation and Education: Theoretical Foundations and Practices. New York: Springer, p. 127-144, 2009.

BLOMMAERT, J. Chronotopes, Scales, and Complexity in the Study of Language in Society. Annual Review of Anthropology, v. 44, p. 105-116, 2015. 
BLOOME, D., PURO, P.; THEODOROU, E. Procedural display and classroom lessons. Curriculum Inquiry, v. 19, n. 3, p. 265-291, 1989.

BLOOME, D.; CARTER, S. P.; CHRISTIAN, B.M.; OTTO, S.; SHUART-FARIS, N. Discourse Analysis and the Study of Classroom Language and Literacy Events: A Microethnographic Perspective. Mahwah: Lawrence Erlbaum Associates, Publishers, 2005.

BLOOME, D.; CARTER, S. P.; CHRISTIAN, B. M.; MADRID, S.; OTTO, S.; SHUARTFARIS, N.; SMITH, M. On Discourse Analysis in Classrooms: Approaches to Language and Literacy Research. Nova York: Teachers College Press, 2008.

BLOOME, D.; BEIERLE, M.; GRIGORENKO, M.; GOLDMAN, S. Learning over Time: uses of intercontextuality, collective memories, and classroom chronotopes in the construction of learning opportunities in a ninth-grade language arts classroom. Language and Education, v. 23, n. 4, p. 313-334, 2009.

BLOOME, D.; KATZ, L.; HONG, H.; MAY-WOODS, P.; WILSON, M. Methodologies in Research on Young Children and Literacy. In: HALL, N. LARSON, J.; MARSH, J. Handbook of Early Childhood Literacy, SAGE Publications, cap. 34, p. 605-632, 2013.

BRICKER, L. A.; BELL, P. Conceptualizations of Argumentation from Science Studies and the Learning Sciences and their Implications for the Practices of Science Education. Science Education, v. 2, n. 3, p. 473-498, 2008.

BROCKRIEDE, W. Where is Argument? In: TRAPP, R.; SCHUETZ, J. Perspectives on argumentation: Essays in Honor of Wayne Brockriede. Illinois: Waveland Press, cap. 1, p. 4-8, 1990.

CADZEN, C. B. Variations in discourse features. In: CADZEN, C. B. Classroom Discourse: The Language of Teaching and Learning. $2^{\text {nd }}$ ed, Portsmouth, 2001.

CARVALHO, A. M. P. Ensino de Ciências por Investigação. $1^{a}$ ed, São Paulo: Cengage Llearning, v. 1, 151p., 2013.

CASTANHEIRA, M. L.; CRAWFORD, T.; DIXON, C.; GREEN, J. Interactional Ethnography: an Approach to Studying the Social Construction of Literate Practices. Linguistics an Education, v. 11, n. 4, p. 353-400, 2001.

DIXON, C.; GREEN J. Studying the discursive constructions of texts in classrooms through interactional ethnography. In: BEACH, R.; GREEN, J.; KAMIL, M.; SHANAHAN, T. Multidisciplinary Perspectives on Literacy Research. Santa Barbara, Hampton Press Cresskill, p. 349-390, 2005.

DRIVER, R.; ASOKO, H.; LEACH, J.; MORTIMER, E. F.; SCOTT, P. Construindo conhecimento científico em sala de aula. Química Nova na Escola. São Paulo, v. 9, n. 31, p. 31-40, 1999.

ERDURAN, S. Methodological Foundations in the Study of Science Classroom Argumentation, In: JIMÉNEZ-ALEIXANDRE; ERDURAN, Argumentation in Science Education: Perspectives from Classroom-Based Research, Springer; Dordrecht, 2008.

FERRAZ, A. T., SASSERON, L. H. Propósitos epistêmicos para a promoção da argumentação em aulas investigativas. Investigações em Ensino de Ciências, v. 22, n. 1, p. 42-60, 2017. 
FRANCO, L. G. S.; ALMEIDA, R. A. F.; CAPPELLE, V. Práticas investigativas em documentos curriculares para os anos iniciais do ensino fundamental: uma análise da primeira proposta de uma base nacional comum curricular. Revista da SbenBio, n. 8, 2016.

FRANCO, L. G. S.; MUNFORD, D. Aprendendo a usar evidências nos Anos Iniciais do Ensino Fundamental ao longo do tempo: um estudo da construção discursiva de formas de responder questões em aulas de ciências. Revista Brasileira de Pesquisa em Educação em Ciências, v. 17, n. 2, p. 661-688, 2017a.

FRANCO, L. G. S.; MUNFORD, D. Quando as crianças argumentam: a construção discursiva do uso de evidências em aulas investigativas de ciências. Investigações em Ensino de Ciências, v. 22, n. 3, p., 2017 b.

FRANCO, L. G. S.; MUNFORD, D. Investigando interações discursivas em aulas de ciências: um "olhar sensível ao contexto" sobre a pesquisa em Educação em Ciências. Revista Brasileira de Pesquisa em Educação em Ciências, v. 18, n. 1, p. 125-151, 2018.

GARFINKEL, H. Studies in Ethnomethodology. Prentice-Hall, Englewood Cliffs, NJ, 1967.

GREEN, J.; DIXON, C.; ZAHARLICK, A. A etnografia como uma lógica de investigação. Educação em Revista, Belo Horizonte. Tradução de Adail Sebastião Rodrigues Júnior e Maria Lúcia Castanheira. v. 42. p. 13-79, 2005.

GREEN, J.; WALLAT, C. Ethnography and language in educational settings. Norwood, NJ: Ablex, 1981.

GREEN, J.; SKUKAUSKAITE, A.; CASTANHEIRA, M. L. Studying the discursive construction of learning lives for individuals and the collective. In: ERSTAD, O.; SEFTONGREEN, J. Identity, Community, and Learning Lives in the Digital Age. Cambridge University Press, 237 p., 2013.

GRIGORENKO, M.; BEIERLE, M.; BLOOME, D. Uses of Collective Memories in Classrooms for Constructing and Taking up Learning Opportunities. In: COMPTONLILLY, C.; HALVERSON, E. (ed.). Time and space in literacy research. New York: Routledge, p. 63-75, 2014.

GUMPERZ, J. J. Discourse Strategies. 1st $^{\text {st }}$ edition. Cambrige University Press, 1982.

HYMES, D. The foundations of sociolinguistics: Sociolinguistic ethnography. Philadelphia: University of Pennsylvania Press, 1974.

IBRAIM, S. S.; JUSTI, R. Teachers' Knowledge in Argumentation: Contributions from an Explicit Teaching in an Initial Teacher Preparation Programme. International Journal of Science Education, v. 38, n. 12, p. 1996-2025, 2016.

JIMÉNEZ-ALEIXANDRE; ERDURAN, S. Argumentation in Science Education: An Overview. In: JIMÉNEZ-ALEIXANDRE; ERDURAN, S. Argumentation in Science Education: perspectives from classroom based research. Springer, cap. 1, p. 03-25, 2008.

JUSTI, R.; MARTINS, M. R.; IBRAIM, S. S. Uma Proposta Alternativa de Análise de Argumentação. Ensenanza de Las Ciencias, v. 35, p. 4479-4483, 2017.

KNIGHT-BARDSLEY, A.; McNEILL, K. L. Science Education Teachers' Pedagogical Design Capacity for Scientific Argumentation. Science Education, v. 100, n. 4, p. 645-672, 2016. 
KELLY, G. J. Discourse, description, and science education. In: YERRICK, R.; ROTH, W. M. (ed.). Establishing Scientific Classroom Discourse Communities: Multiple Voices of Research on Teaching and Learning, Mahwah, NJ: Lawrence Erlbaum Associates, cap. 3, p. 79-108, 2005.

KUHN, D. Science as argument: implications for teaching and learning scientific thinking. Science Education, v. 77, n.3, p. 319-337, 1993.

MANZ, E. Examining Evidence Construction as the Transformation of the Material World into Community Knowledge. Journal of Research in Science Teaching, v. 52, n. 1, p. 1-28, 2015a.

MANZ, E. Representing Student Argumentation as Functionally Emergent From Scientific Activity. Review of Educational Research, v. 85, n. 4, p. 553-590, 2015 b.

MANZ, E.; RENGA, I. P. Understanding how teachers guide evidence construction conversations. Science Education, v. 101, n.4, p. 584-615, 2017.

MARTINS, M.; IBRAIM, S. de S.; MENDONÇA, P. C. C. Esquemas argumentativos de Walton na análise de argumentos de professores de química em formação inicial. Ens. Pesq. Educ. Ciênc., v.18, n.2, p. 49-71, 2016.

McDONALD, S. P.; KELLY, G. J. Beyond Argumentation: Sense-Making Discourse in the Science Classroom. In: KHINE, M. S. (ed.) Perspectives on Scientific Argumentation: Theory, Practice and Research. Springer, cap. 13, p. 265-281, 2012.

McNEILL, K. L. Elementary Student's views of explanation, argumentation, and evidence, and their abilities to construct arguments over the school year. Journal of Research in Science Teaching, v. 48, n. 7, p. 793-823, 2011.

MERCER, N., DAWESB, L.; WEGERIFA, R.; SAMS, C. Reasoning as a scientist: ways of helping children to use language to learn science. British Educational Research Journal, v. 30, n. 3, p. 359-377, 2004.

MIRZA, N. M.; PERRET-CLERMONT, A. N. Introduction. In: MIRZA, N. M.; PERRETCLERMONT, A. (ed.). Argumentation and Education: Theoretical Foundations and Practices. New York: Springer, p. 127-144, 2009.

MITCHELL, C. J. Typicality and the case study. In: ELLENS, R. F. (ed.), Ethnographic research: A guide to general conduct. New York: Academic Press, 1984.

MONTEIRA, S. F.; JIMENEZ-ALEIXANDRE, M. P. The Practice of Using Evidence in Kindergarten: The Role of Purposeful Observation. Journal of Research in Science Teaching, v. 53, n. 8, p. 1232-1258, 2016.

MUNFORD, D.; LIMA, M. E. C. C. Ensinar ciências por investigação: em que estamos de acordo? Ensaio Pesquisa em Educação em Ciências, v. 9, n. 1, 2007.

MUNFORD, D.; TELES, A. P. S. S. Argumentação e a construção de oportunidades de aprendizagem em aulas de ciências. Ensaio Pesquisa em Educação em Ciências, v. 17, n. especial, p. 161-185, 2015.

NAYLOR, S.; KEOGH, B.; DOWNING, B. Argumentation and Primary Science. Research in Science Education, v. 37, n. 1, p. 17-39, 2007. 
NATIONAL RESEARCH COUNCIL. Inquiry and the National Science Standards: A guide for teaching and learning. New York, National Academy Press, 2000.

OLIVEIRA, A. W.; AKERSON, V. L.; OLDFIELD, M. Environmental Argumentation as Sociocultural Activity. Journal of Research in Science Teaching, v. 49, n. 7, p. 869-897, 2012.

PIZARRO, M. V.; BARROS, R. C. dos S. N.; LOPES JUNIOR, J. Os professores dos anos iniciais e o ensino de Ciências: uma relação de empenho e desafios no contexto da implantação de Expectativas de Aprendizagem para Ciências. Revista Brasileira de Pesquisa em Educação em Ciências, v.16, n. 2, p. 421-448, 2016.

RATZ, S. V. S.; MOTOKANE, M. T. A construção dos dados de argumentos em uma Sequência Didática Investigativa em Ecologia. Ciência \& Educação, v. 22, n. 4, p. 951-973, 2016.

RYU, S.; SANDOVAL, W. A. Improvements to Elementary Children's Epistemic Understanding from sustained Argumentation. Science Education, v. 86, n. 3, p. 488-526, 2012.

SANDOVAL, W. A.; ÇAM, A. Elementary Children's Judgments of the Epistemic Status of Sources of Justification. Science Education, v. 95, n. 3, p. 383-408, 2011.

SASSERON, L. H.; CARVALHO, A. M. P. Uma análise de referenciais teóricos sobre a estrutura do argumento para estudos de argumentação no ensino de ciências. Ensaio, v. 13, n. 3, p. 243-262, 2011.

SASSERON, L. H.; CARVALHO, A. M. P. A construção de argumentos em aulas de ciências: o papel dos dados, evidências, e variáveis no estabelecimento de justificativas. Ciência \& Educação, v. 20, n. 2, p. 393-410, 2014.

SCARPA, D. L. O papel da argumentação no ensino de ciências: lições de um workshop. Revista Ensaio, Belo Horizonte, v.17, n. especial, p. 15-30, novembro, 2015.

SCARPA, D. L.; TRIVELATO, S. L. F. Movimentos entre a cultura escolar e cultura científica: análise de argumentos em diferentes contextos. Revista Internacional de Investigación en Educación, Edición especial Enseñanza de las ciencias y diversidad cultural, v. 6, n. 12, p. 69-85, 2013.

SILVA, M. B.; TRIVELATO, S. L. F. A mobilização do conhecimento teórico e empírico na produção de explicações e argumentos numa atividade investigativa de Biologia. Investigações em Ensino de Ciências, v. 22, n. 2, p. 139-153, 2017.

STREET, B. V. Cross-cultural approaches to literacy. Cambridge: CUP, 1993.

TOULMIN, S. E. O layout do argumento. In: TOULMIN, S. E. Os usos do argumento. Tradução de Reinaldo Guarany. $2^{a}$ ed. São Paulo: Martins Fontes, p. 135-207, 2006.

VAN EEMEREN; GROOTENDORST, R.; HENKEMANS, A. F. S. Argumentation: Analysis, Evaluation, Presentation. New Jersey: Lawrence Erlbaum Associates, 2002.

VARELAS, M; PAPPAS, C. C.; KANE, J.; ARSENAULT, A.; HANKES, J.; COWAN, B. M. Urban primary-grade children think and talk science: Curricular and instructional practices that nurture participation and argumentation. Science Education, v. 92, n. 1, p. 65-95, 2008.

YUN, S. M.; KIM, H. Changes in Students' Participation and Small Group Norms in Scientific Argumentation. Research in Science Education, Springer, v. 45, n. 3, p. 465-484, 2015. 
NOTAS

${ }^{1}$ Os dados fazem parte de uma pesquisa mais ampla em que uma mesma turma foi acompanhada ao longo dos três primeiros anos do Ensino Fundamental. Esta pesquisa recebeu autorização da diretoria da escola e do comitê de ética da instituição responsável. Houve conversas com as crianças sobre o estudo e como dos dados seriam utilizados. Os adultos envolvidos - pais, professora e estagiários - assinaram um Termo de Consentimento. Pseudônimos foram adotados para identificação dos participantes.

${ }^{2}$ Os símbolos presentes no quadro têm os seguintes significados: $\uparrow$ (aumento da entonação no final da fala); $\downarrow$ (diminuição da entonação); XXXX (fala indecifrável); ênfase; $\boldsymbol{\Delta}$ (maior volume); $\boldsymbol{\Delta} \boldsymbol{\Delta}$ (grande aumento de volume); $\boldsymbol{\nabla}$ (menor volume); enunciado com maior velocidade; ${ }^{\mathrm{L}} \Gamma$ (sobreposição de falas); vogal+ (vogal alongada); Comportamento não verbal em itálico; I (pausa); IIII (pausa longa); - (palavra incompleta).

${ }^{3}$ Para consultar como outras pistas contextuais foram analisadas nessa interação e em outros eventos relacionados, ver Franco e Munford (2017a, 2017b).

${ }^{4}$ Informações coletadas por meio de aplicação de questionário respondido pelas famílias das crianças. Para identificação da etnia foram utilizados os critérios adotados pelo IBGE (Instituto Brasileiro de Geografia e Estatística), que resultaram nas categorias: brancos (B), pardos (P), indígena (I) e não declarado (ND). No campo Renda Familiar, "SR" corresponde a sem renda e "S" corresponde a salário mínimo.

Submetido: $20 / 07 / 2017$

Aprovado: 06/03/2018

Contato:

Centro de Ciências Naturais e Humanas

Universidade Federal de ABC

Avenida dos Estados, 5001, Santo André, São Paulo $\mid$ SP $\mid$ Brasil

CEP 09.201-580 